\title{
CURRÍCULO-DOCUMENTO, CURRÍCULOS-PERFORMANCE
}

\author{
LUCIANA ATHAYDE PAZ ${ }^{1 ; *}$ \\ ORCID: https://orcid.org/0000-0003-0630-7778 \\ GILBERTO ICLE ${ }^{1 ; 2 ; * *}$ \\ ORCID: https://orcid.org/0000-0001-7961-4782
}

\begin{abstract}
RESUMO: Neste texto busca-se mostrar o enlace entre currículos e performance. Tal intento se opõe à noção de currículo como documento. Circunscreve-se as noções de ficção e de corpo no campo da performance, bem como nas produções que entrelaçam os Estudos da Performance com o campo da Educação. Apresenta-se uma revisão das principais referências sobre Performance e Educação, assim como discute-se a primazia da lógica do documento, da materialidade e do visível em detrimento da transmissão da memória e do conhecimento por meio das práticas incorporadas, em razão de sua efemeridade. Defende-se que a perspectiva da performance, tendo como operadores as noções de corpo e ficção, permite compreender a efemeridade como parte constituinte das práticas de transmissão de memória e de conhecimento. Propõe-se currículos-performance, em oposição ao conceito de currículodocumento, como possibilidade de inconstância nos processos de construção dos conhecimentos.
\end{abstract}

Palavras-chave: Currículo, Performance, Corpo, Ficção.

\section{CURRICULUM DOCUMENT, CURRICULUM PERFORMANCE}

\begin{abstract}
This text is aimed at showing the link between curricula and performance. This intent is opposed to the notion of curriculum as document. The notions of fiction and body are included in the field of performance, as well as in the productions that intertwine Performance Studies and the field of Education. A review of the main references on Performance and Education is presented. It is discussed the preeminence of the logic of the document, the actuality and the visible in detriment of memory and knowledge transmission by means of the embodied practices, for their ephemerality. It is claimed that the performance perspective, having as operators the notions of body and fiction, allows to understand ephemerality as a constituent part of the practices of memory and knowledge transmission. Performance curricula, opposing to the idea of document curriculum, are proposed as a possibility of inconstancy in the processes of knowledge construction.

\footnotetext{
${ }^{1}$ Faculdade de Educação da Universidade Federal do Rio Grande do Sul (UFRGS). Porto Alegre, RS, Brasil.

2 Universidade de Brasília (UnB). Brasília, DF, Brasil.

* Doutoranda do Programa de Pós-graduação em Educação da Faculdade de Educação da Universidade Federal do Rio Grande do Sul (UFRGS). Porto Alegre, RS, Brasil. <lukkadoutorado@gmail.com>. O presente trabalho foi realizado com apoio da Coordenação de Aperfeiçoamento de Pessoal de Nível Superior - CAPES.

** Professor permanente no Programa de Pós-gradução em Educação da Universidade Federal do Rio Grande do Sul (UFRGS). Porto Alegre, RS, Brasil e do Programa de de Pós-graduação em Artes Cênicas da Universidade de Brasília (UnB). Brasília, DF, Brasil. <gilbertoicle@gmail.com>. O presente trabalho foi realizado com apoio do Conselho Nacional de Desenvolvimento Científico e Tecnológico - CNPq. 
Keywords: Curriculum, Performance, Body, Fiction.

\section{CURRÍCULO-DOCUMENTO, CURRÍCULO-PERFORMANCE}

RESUMEN: En este texto se busca mostrar el vínculo entre los currículos y la performance. Este intento se opone a la noción de currículo como documento. Se limitan las nociones de ficción y de cuerpo en el campo de la performance, así como en las producciones que entrelazan los Estudios de la Performance con el campo de la Educación. Se discute la primacía de la lógica del documento, de la materialidad y de lo visible en perjuicio de la transmisión de la memoria y del conocimiento por medio de prácticas incorporadas, por su carácter efímero. Se defiende que la perspectiva de la performance, teniendo como operadores las nociones de cuerpo y ficción, permite comprender el carácter efímero como parte constitutiva de las prácticas de transmisión de memoria y de conocimiento. Se propone currículos performance, en oposición a la idea de currículo documento, como posibilidad de inconstancia en los procesos de construcción de los conocimientos.

Palabras clave: Currículo, Performance, Cuerpo, Ficción.

\section{INTRODUÇÃO}

O volume 36 da célebre coletânea Asterix, intitulado O Papiro de César (GOSCINNY, 2015), conta como os irredutíveis gauleses conseguiram que sua versão da história sobre a resistência às conquistas do Império Romano passasse de geração a geração, chegando até os tempos atuais. A história em quadrinhos conta que César, ao escrever suas memórias sobre as guerras contra os gauleses, é aconselhado por seu editor a suprimir o capítulo no qual narra as derrotas sofridas diante da aldeia de Asterix. Não obstante, um dos escribas (mudos) entrega uma cópia a um repórter gaulês que a leva à aldeia de Asterix. Os gauleses ficam furiosos e incomodados por serem omitidos das memórias escritas de César e buscam garantir que seus feitos sejam passados de geração a geração por meio dos Druidas, responsáveis por transmitir os ensinamentos gauleses. Os autores, ao longo da história, apresentam diálogos, tanto romanos quanto gauleses, nos quais os personagens defendem o modo como difundem às gerações futuras sua história e seus conhecimentos. Os romanos defendem o registro escrito, a organização burocrática, os documentos. Os gauleses, por sua vez, desconfiam da escrita e investem na memória, na oralidade, nos corpos.

É possível que a maioria de nós, imersos numa cultura sobremaneira centrada na suposta veracidade dos documentos, ache risível a frase proferida pelo Druida Panoramix ao ser informado que Obelix ficou deprimido ao ler o seu horóscopo. Espantado, o velho ancião diz: "é... as pessoas tendem a crer no que está escrito! Um fenômeno estranho!” (GOSCINNY, 2015, p. 8). O risível que há para nós na frase proferida por Panoramix, assim como em todo o trabalho dos gauleses para encontrar o Druida responsável por guardar os conhecimentos e a história e para ele relatar o que estava escrito no pergaminho de César, não retrata, de certo modo, o cômico ou questionável que há em nossa crença nos documentos?

O campo dos Estudos da Performance vem desde os anos de 1970 questionando e desafiando a preeminência dos documentos escritos na constituição dos saberes científicos no Ocidente, e cremos que tal provocação reverbera nessa e em outras verdades que tomamos como irreprocháveis no campo da educação. Com efeito, ao considerar a performance também como "[...] um sistema de aprendizagem, armazenamento e transmissão de conhecimento, os estudos da performance nos permitem ampliar o que entendemos por 'conhecimento' [...] ao mudar o foco da cultura escrita para a cultura incorporada" (TAYLOR, 2013, p. 45). Essa perspectiva, própria da performance, sugere conexões entre o conhecimento e a memória sem a pretensão da referência a um original, permanente ou fixo, mas compreendendo a efemeridade como parte indissociável da memória e do conhecimento. 
A performance, ao tramar-se com o campo da Educação, entre outras questões, nos interpela sobre: conhecimento/verdade (ficção), corpo e documento.

As concepções mais arcaicas de currículo o tomam como um documento no qual estão previstos os conhecimentos que tem mérito suficiente para serem ensinados e aprendidos na Escola. Tal concepção, com efeito, está assentada na ideia de que, como documento, o currículo é um operador rígido e reto, uma vez que ele deve ser seguido por supostamente encerrar em si mesmo tanto a justificativa para os conhecimentos que devem ser aprendidos, quanto o elenco de tópicos que precisam ser atingidos. Um conjunto de autores brasileiros do campo do currículo tem se esforçado para criticar tal concepção, estamos nos referindo particularmente aos trabalhos de Macedo (2006; 2012; 2016), Costa e Lopes (2018), Costa e Wortmann (2016), Moreira (2003), Veiga-Neto (2002; 2014), Traversini (2012), Lockmann e Traversini (2017), Traversini, Reis e Steffen (2018), Oliveira e Paraíso (2013) Paraíso (2014, 2018) e Frangella (2016).

Tomá-lo como documento, portanto, não apenas o coloca no centro das preocupações racionalistas como também estabelece um tipo de relação unilateral própria de relações de poder pouco móveis, que sustentam os saberes e conhecimentos como fixos, como algo a ser apreendido, tomado para si.

Nós gostaríamos, neste texto, de nos contrapor a essa concepção de currículo, mostrando como poderíamos pensá-lo, e como ele seria um dispositivo mais potente para a escola, ao tomá-lo como performance e não como mero documento.

Esse debate, entre documento e performance, é próprio do campo, em emergência no Brasil, conhecido como Performance e Educação, e que, apesar de recente, conta com produções que nos serão caras neste texto para compreendermos a potência da noção de performance na Educação, sobretudo no caso do currículo. Diferentes ideias sobre as relações entre Performance e Educação podem ser encontradas na produção brasileira e em língua portuguesa nos últimos anos, entretanto, nos interessa chamar a atenção aqui para a ideia de Performance como disparador por intermédio do qual reorganizamos o que sabemos sobre a Escola. Essa ideia está especialmente desenvolvida em Pineau (2010; 2013), Schechner, Icle e Pereira (2010), Icle (2010; 2013), Icle, Bonatto e Pereira (2017), Pereira (2010; 2012; 2013; 2017), Machado (2010), Silva (2012), Ciotti (1999, 2014), Rachel (2013, 2015), Araújo (2013), André (2007; 2017), Hartmann (2013; 2017), Bonatto (2015), Bonatto e Icle (2017), Caon (2017), Pereira e Conte (2013) e Pereira e Icle (2018).

Assim, ao partir desse caldo epistemológico próprio do campo da Performance, propomonos, na sequência, mostrar o enlace entre currículo e Performance por intermédio de dois operadores: a ficção e o corpo. Isso nos permitirá, acreditamos, apartar-nos de um currículo-documento para nos aproximarmos de um currículo-performance, compreendido como uma forma de tomarmos a inconstância não como um problema, mas como próprio da Educação.

\section{PERFORMANCE E EDUCAÇÃO: ENTRE DOCUMENTO E CORPOS}

Nesta última década, os estudos que entretecem performance e educação no Brasil apontam para uma significativa produção para pensar e analisar as práticas escolares no tocante à docência, aos corpos e aos saberes, aos usos dos espaços-tempos a partir, sobretudo, das disciplinas de artes visuais e de teatro. No entanto, Bonatto e Icle (2017) apontam para a potência da performance ${ }^{3}$ no espaço escolar não somente como linguagem artística, desenvolvida nas disciplinas de artes, mas também no seu transbordamento para as práticas escolares. Para os autores, a performance no campo da educação, mormente no que tange às análises da escola, é potente tanto para analisar as práticas escolares como performance, quanto na construção de interações performativas na pedagogia.

A perspectiva de performance que tomamos aqui, portanto, provém de duas acepções de performance usuais no campo dos Estudos da Performance, a saber: a arte da performance e a performance social.

\footnotetext{
${ }^{3}$ Não estamos aqui tomando a noção de Performance a partir da ideia de desempenho, desenvolvida em relação à performatividade, como nos trabalhos de Ball (2010) e Anderson (2010). 
A arte da performance caracteriza-se, antes de tudo, pela impossibilidade de definições fechadas ${ }^{4}$. Para Eleonora Fabião (2009, p. 63), tentar definir performance é dedicar-se a uma tarefa inócua, um equívoco. A autora prefere questionar-se sobre "[...] o que move a performance e o que a performance é capaz de mover. Estrategicamente, a performance escapa a qualquer formatação, tanto em termos das mídias empregadas quanto dos materiais ou espaços utilizados". A estratégia adotada por Fabião com a finalidade de estudo da performance como linguagem centra-se em traçar "tendências dramatúrgicas" do que a autora nomina de programas performativos ${ }^{5}$. Para ela, as ações dos performers, ainda que contem com improviso, na medida em que não são sempre previamente ensaiadas, são calculadas e elaboradas a fim de suscitar algo nas pessoas afetadas pela ação. Há em toda performance uma intencionalidade, na maior parte das vezes de suspender ou profanar aquilo que socialmente já está naturalizado, disposto como uma verdade. Fabião entende que os programas, ou seja, essas ações “[...] disseminam dissonâncias diversas, dissonâncias de ordem econômica, política, emocional, orgânica, ideológica, psicológica, espiritual, identitária, sensorial, sexual, social, racial. [...] Programas anunciam que 'corpos' são sistemas relacionais abertos, altamente suscetíveis e cambiantes"' (FABIÃO, 2009, p. 63).

A performance social, por sua vez, surge como um modo de compreender a complexidade das relações do mundo, no qual as "[...] populações e ideias movem-se, empurradas por guerras e governos despóticos, por forças econômicas, que de modo cortês chamamos de 'mercado', pela internet e outras novas tecnologias de comunicação" (SCHECHNER, 2000, p. 12) ${ }^{6}$. Ou seja, dedica-se a estudar as múltiplas cenas do mundo contemporâneo como performance, por meio da inter e da transdisciplinariedade. Assim, o campo dos Estudos da Performance não se restringe somente às manifestações artísticas, como objeto de estudo, mas igualmente a

[...] ritos cerimoniais humanos e animais, seculares e sagrados; representação e jogos; performances da vida cotidiana; papéis da vida familiar, social e profissional; ação política, demonstrações, campanhas eleitorais e modos de governo, esportes e outros entretenimentos populares; psicoterapias dialógicas e orientadas sobre o corpo, junto com outras formas de cura (como o xamanismo); os meios de comunicação. O campo não tem limites fixos (SCHECHNER, 2000, p. 12) ${ }^{7}$.

É esse híbrido entre performance social e arte da performance, característico do campo dos Estudos da Performance, que tem fundamentado as pesquisas que enovelam os campos da performance e da educação. No campo da Educação, segundo Pereira (2012, p. 294), confluem os três contextos da performance elencados por Conquergood (2002, p. 18 apud PEREIRA, 2012, p. 292). Seriam eles: contexto aplicado; contexto analítico e contexto de realização. No contexto aplicado, a performance "[...] aparece mais como ação performativa, porquanto aspecto de determinado tipo de enunciação, e não propriamente uma linguagem constituída por signos, códigos, normatizações” (PEREIRA, 2012, p. 292). O contexto aplicado tem relação com o campo da comunicação. O contexto analítico tem a ver com o campo da cultura. Seria a análise das performances culturais nas quais os indivíduos (atores sociais) desempenham funções (papéis sociais), nem sempre de modo consciente, que constituem o que Turner (1974) designou como dramas sociais.

\footnotetext{
${ }^{4}$ Sobre Performance e o campo dos Estudos da Performance, o leitor e a leitora podem acessar: Ayerbe (2017), Pinto (2015), Roques (2017), Medeiros (2014), Agra (2014), Icle (2011), Bonfitto (2014). Alguns desses trabalhos versam sobre temas aqui desenvolvidos, ainda que com abordagens diferentes e não no campo da Educação.

${ }^{5}$ Fabião se vale do termo programa "[...] para referir-se às ações elaboradas pelo artista, tendo como inspiração o texto Como criar para si um corpo sem órgãos, de Deleuze", no qual ele "[...] propõe que o programa é motor de experimentação" (FABIÃO, 2009, p. 63).

${ }^{6}$ No original em espanhol: “[...] poblaciones y las ideas se mueven, empujadas por guerras y gobiernos despóticos, por fuerzas econômicas as las que cortésmente llamamos 'mercado', por el internet y otras nuevas tecnologías de la comunicación” (SCHECHNER, 2000, p. 11-12).

${ }^{7}$ No original em espanhol: “[...] ritos ceremoniales humanos y animales, seculares y sagrados; representación y juegos; performances de la vida cotidiana; papeles de la vida familiar, social y profesional; acción política, demostraciones, campañas electorales y modos de gobierno; deportes y otros entretenimientos populares; psicoterapias dialógicas y orientadas hacia el cuerpo, junto con otras formas de curación (como el shamanismo); los medios de comunicación. El campo no tiene límites fijos" (SCHECHNER, 2000, p. 12).
} 
O contexto de realização diz respeito à criação, ao estudo da criação artística, à produção discursiva que as obras potencializam ou questionam, associando corpos a determinados discursos "[...] de tal modo que eles se retroalimentam corpo-discurso, discurso-corpo, forma-corpo, corpo-forma" (PEREIRA, 2012, p. 293). Na perspectiva do autor, esses três contextos da performance imbricam-se na educação, posto que nela há cultura, arte (invenção) e comunicação.

Tal entretecimento entre educação e performance, nos permitirá, talvez, desestabilizar determinadas naturalizações acerca das escolas e dos currículos. Essa desestabilização poderia ser pensada pelo viés de um denominador comum: o corpo. Ente esquecido e subjugado na Escola, o corpo condensaria aqui cultura, arte e comunicação numa só experiência. Eis um aspecto que poderia enlaçar as dimensões recém descritas. $\mathrm{Na}$ Educação, o corpo é instrumento e sujeito de cultura, consiste num receptáculo ao mesmo tempo que é o operador da arte e, ainda, entrelaça em si mensagem, comunicador, receptor. Ele desestabiliza, portanto, todas essas categorias quando tomadas de forma individual. A performance supõe um corpo indivisível.

O corpo, no que concerne à performance, não é "apenas um conjunto de órgãos e tecidos, mas o suporte de nossa subjetividade" (PEREIRA, 2012, p. 306). Logo, a performance produz, como sugere Pereira (2012), um corpo-discurso, corpo-forma, que ora reforça as relações hegemônicas, ora as rompe, transfigurando-as.

Assim, os corpos tanto são produzidos por meio das performances quanto performam, isto é, produzem conhecimentos sobre si e sobre outros corpos. Ao compreender o corpo para além de um conjunto de órgãos, mas também em sua subjetividade, é possível, segundo Taylor (2013, p. 62), "enfrentar a construção social dos corpos em contextos particulares", considerando tanto os atributos como sexo, etnia, idade, status quanto sua função social. Ou seja, concebe-se o corpo em suas dimensões históricas, culturais e sociais, assim como a atuação de distintos corpos em relação e o que tal relação produz. No que tange à educação, poder-se-ia pensar nos corpos que habitam e relacionam-se entre si, constituindo assim o corpo escolar. Instigada a pensar os corpos da escola e práticas que criam fissuras nos corpos já institucionalizados, Bonatto (2015) nos convida a pensar os corpos sociais de professores e estudantes como performers, isto é, como professores-performer e estudantes-performer. O convite de Bonatto distancia-se da ideia difundida do professor-ator, que vê o papel do professor muito mais como um animador dos alunos, com a finalidade de afastar o tédio de aprender. Tal perspectiva está associada a uma noção de teatro que vê o espectador como um corpo passivo que apenas recebe. Trata-se de uma concepção muito similar ao que Paulo Freire (1987, p. 33) entendia como educação bancária, na qual o aluno é uma espécie de receptáculo de informações do professor e este deve ser interessante o suficiente para que o aluno permita que o conteúdo seja passado a ele. Bonatto (2015, p.114), ao contrário, defende que professor-performer e estudantes-performers atuam como coautores na criação, pondo em xeque a relação hierárquica já naturalizada do espaço escolar, na qual o professor ocupa o espaço do saber e o aluno do não saber. Essa alomorfia das relações potencializa o engendro de novas práticas escolares.

Pensar o corpo como produtor de conhecimento (TAYLOR, 2013) permite ressignificar nossas funções sociais, nossas relações. Como sugere Bonatto (2015), ressignificar os corpos professores e corpos estudantes vendo-os como performers contingencia relações mais horizontais, fluidas e tira do aluno a pecha do corpo passivo.

Estes corpos, de professor-performer e estudante-performer, potencializam processos de produção de conhecimentos coletivos com espaço para a pluralidade dos corpos. Para Pineau, a poética da performance educacional privilegia do mesmo modo as dimensões criativas e construídas da prática pedagógica. Ela reconhece que educadores e educandos não estão engajados na busca por verdades, mas sim em ficções colaborativas - continuamente criando e recriando visões de mundo e suas posições contingentes dentro delas. Uma poética educacional privilegia as múltiplas histórias e os múltiplos narradores no processo em que as narrativas da experiência humana são modeladas e compartilhadas por todos os participantes em um coletivo de performance (PINEAU, 2010, p. 97).

Essa visão pedagógica de Pineau é compartilhada, em alguma medida, pelos autores do campo do currículo abordados por nós neste texto, antagônicos a uma concepção de currículo em que a questão central seja sobre o que deve ser ensinado. Esta perspectiva, que compreende o currículo somente como a lista dos conteúdos a serem ensinados, um currículo-documento, remete a uma 
indagação mais ampla "o que constitui conhecimento válido e verdadeiro?”. Tradicionalmente, essa última pergunta tem sido respondida aludindo-se "[...] a teorias que adotam, de uma forma ou de outra, uma concepção do conhecimento como representação (verdadeira), como correspondência ou adequação a alguma suposta e preexistente realidade, a alguma presumida coisa em si" (SILVA, 2002, p. $37)$.

É justamente essa noção de conhecimento preexistente ou fixo que a pedagogia performativa vai questionar, por meio da noção de ficção. Esse aspecto evidencia-se em Machado (2010) e Hartmann (2017). Ambas as autoras partem do pressuposto de que as crianças tanto reproduzem quanto criam performances em seus cotidianos, as crianças são performers, produzem conhecimentos e com isso criam brechas e suspendem os papéis sociais. Essa perspectiva, que abrange o conhecimento como algo a ser criado coletivamente, pois entende as crianças, os estudantes, como partícipes em sua construção, denota que as relações entre ficção e corpo são dimensões relevantes para pensarmos currículos-performance.

Outra questão do currículo-documento que a performance suspende é sobre quem se deseja formar. A inquirição sobre o que deve ser ensinado nunca está separada de outra importante pergunta: “o que eles ou elas devem ser?” (SILVA, 2010, p. 15). Ao pensar quais corpos tenciona formar, definese quais os conhecimentos que serão ensinados, hierarquizando tais saberes, "[...] colocando em evidência aquilo que é mais ou menos importante na formação dos sujeitos, ligado, com efeito, a um projeto de Educação e de mundo que lhe confere sentido" (ICLE, 2013, p. 18). Acreditamos que a noção de currículo que nos permite pensar um currículo-performance está, num primeiro momento, em conformidade com a noção do campo dos Estudos Culturais. Tal noção alude que não só a escola produz currículos, visto que estes estão em estreita correspondência com a cultura, mas que outras esferas da cultura produzem currículos, dado que nos constituem como sujeitos, nos subjetivam. Destarte, não só os conteúdos escolares elencados de modo intencional seriam currículo, outrossim, nossas experiências em outras instâncias da cultura instituem currículos. Essa noção, que expande o currículo para além dos muros da escola, nominada como currículos culturais, nos permite conjecturar que os currículos escolares são engendrados tanto pelos conteúdos explícitos, quanto pelos implícitos, como as práticas, metodologias, usos dos espaços escolares e as relações interpessoais. Nossa perspectiva curricular, em consonância com Santos (2017, p. 5), compreende que os currículos escolares são "o conjunto de experiências que o aluno vivencia na escola ou sob a supervisão dessa instituição". Para além dos conhecimentos acadêmicos, somam-se outras dimensões do aprender.

Tal noção de currículo, apresentada por Santos (2017), requer que façamos um exercício extremamente difícil para nossa cultura, regida pela lógica do suposto controle que os documentos nos proporcionam, porquanto amplia o lastro curricular e engloba na ideia de currículo as condutas e subjetividades de alunos e professores.

Araújo (2013) parte dos Cadernos do Professor e dos Cadernos dos Alunos para pensar o currículo de artes proposto para a Rede Pública de Ensino de São Paulo, em que prevê o ensino de performance como linguagem para o Ensino Médio. O autor aponta, com esse exercício, as fricções entre o proposto nos cadernos, a produção poética dos alunos e a reação da instituição escolar. Para Araújo, as ações tendem a ser esvaziadas pelo posicionamento político da escola. Contudo, na perspectiva de um currículo-performance, todo esse emaranhado de relações produz conhecimento, produz currículos. Em certa medida, dizer que as ações se esvaziam em virtude do posicionamento da escola é considerar que existe um modelo documental a ser seguido, o qual prevê, supostamente, a verdadeira maneira de ensinar performance. Mas precisamos considerar que tanto o documento que propõe o conteúdo e as criações poéticas dos alunos, quanto o afeto gerado pelo conjecturado público, constituem um currículo-performance. Seria justamente o jogo de relações, as tensões das relações entre o documento, os corpos-alunos, os corpos-instituição que produzirão conhecimento sobre nossas performances. Por essa razão, acreditamos que pensar currículos-performance nos convoca a repensar, inclusive, sobre os nossos métodos de análise, buscando fugir de nossa habitual tendência a pensar a partir da lógica do documento, que nos conduz, muitas vezes, a um olhar dual mediante o qual unicamente enxergamos (certo-errado, bem-mal, sucesso-fracasso, adesão-rejeição) e perdemos a possibilidade de analisar a complexidade que as relações dos corpos entre si e com os documentos produzem. Talvez o deslocamento de nosso olhar analítico inicie pela recusa em "aceitar distinções entre 
o currículo formal e o currículo vivido (em suas várias nuances)" (MACEDO, 2006, p. 288). A autora não se refere somente às

[...] distinções didáticas, mas principalmente às consequências que elas têm tido para o estudo das políticas e das práticas curriculares. [...] a produção dos currículos formais e a vivência do currículo são processos cotidianos de produção cultural, que envolvem relações de poder tanto em nível macro quanto micro. Em ambos são negociadas diferenças (MACEDO, 2006, p. 288).

Por essa razão, acreditamos que as fricções nos jogos de relação entre documento, produção poética e manifestação dos afetos produzem conhecimento, produzem saberes e de fato constituem o que designamos neste estudo como os currículos-performance.

No entanto, o deslocar de nossos prismas de análise e prática nos coloca diante de, no mínimo, duas questões caras também às teorizações do campo do currículo: ficção (conhecimento/verdade) e a relação corpo/documento.

\section{FICÇÃO, CONHECIMENTO E VERDADE: TRAMAS ENTRE CURRÍCULO E PERFORMANCE}

Acreditamos que um dos pontos centrais para deslocar nossa maneira habitual de ver o currículo é perquirir o que entendemos como ficção. Flusser (1966) aponta que o tema da ficção do mundo ou a metáfora do mundo como ficção apresenta-se ao longo de toda a história do pensamento ocidental, e de modo sintético o autor apresenta alguns exemplos: "Platão (vemos apenas sombras); Cristianismo medieval (o mundo é uma armadilha montada pelo diabo); Renascimento (o mundo é um sonho); Barroco (o mundo é teatro); Romantismo (o mundo é minha representação); Impressionismo (o mundo é como se)" (FLUSSER, 1966, p. 1). No entanto, todos esses exemplos conferem ao mundo, ou ao conhecimento de mundo, traços de ficção se comparado à determinada realidade, assim, sob esse prisma, ficção seria o contrário de realidade. Isto é, todos eles partem da ideia de que há uma realidade ancorada numa suposta verdade. O Mito da Caverna de Platão ainda hoje baliza com força as noções de conhecimento, verdade e aparência. Para Platão, vemos as sombras, mas há outro espaço no qual estão as imagens que produzem as sombras, logo, há o espaço das imagens verdadeiras. Devemos lutar para sair da caverna, do mundo das aparências, das ilusões, em direção à luz do exterior da caverna, onde descobriremos a verdade, teremos acesso ao verdadeiro conhecimento. Assim, vale pensar que o conhecimento é a busca por descobrir esse espaço no qual está a verdade, ou melhor, há verdades para serem descobertas e há ficções que deturpam e ludibriam nossa percepção daquilo que é verdadeiro. A escola, ou o conhecimento escolar, organizado por meio de um currículo, teria a função de tirar-nos da caverna. Por conseguinte, ficção e, em certa medida, o teatro firmaram-se ao longo de grande parte da história do pensamento como antagônicos à realidade, como ilusão e consequentemente como mentira. A ficção se configura, nesse prisma, como algo no âmbito do não-real, da não verdade.

$\mathrm{Na}$ perspectiva teórica por nós adotada, poder-se-ia dizer que a verdade é algo da ordem do ficcional. Trata-se de tomar

[…] a verdade como ficção, invenção, e criação. Uma visão perspectivista e interpretativa do conhecimento. O conceito como produção e intervenção e não como descoberta ou reflexo. A insistência no caráter produtivo da linguagem. O privilegiamento da diferença e da multiplicidade em detrimento da identidade e da mesmidade. Rejeição da transcendentalidade e da originalidade do sujeito. O caráter heterogêneo, derivado das formações da subjetividade. A não-identidade do 'sujeito' consigo mesmo. A opção por uma genealogia em detrimento de ontologia. A pesquisa não das essências e das substâncias, mas das forças e das intensidades [...] O devir em vez do ser. Não valores, mas sua valoração. Não a moral, mas sua proveniência (SILVA, 2002, p. 35).

Esse olhar para a noção de ficção e seus desdobramentos na discussão sobre conhecimento e verdade não são novos, de forma mais contundente podemos encontrá-los na obra de Nietzsche. A verdade e o conhecimento, os valores e o sujeito, têm centralidade na obra do pensador alemão. Sua obra 
produziu grande influência na relevante ruptura ou virada conceitual em meados do século XX, em que ficção não é compreendida então como o contrário de real ou de verdade, mas como o processo pelo qual algo ou alguém passou a constituir-se como verdade e conhecimento. Tampouco ficção é algo que “[...] fazemos nas horas de folga em que não estamos descobrindo a verdade. É a nossa única atividade. E depois não se trata de uma atividade desprezível, nem as ficções são um produto inútil. As ficções são a nossa vida. Elas são a nossa verdade" (SILVA, 2002, p. 39). Ao questionar a verdade, Nietzsche desloca o antagonismo entre ficção e realidade ou ficção e verdade. $O$ autor afirma que a verdade não é algo a ser encontrado ou descoberto, visto que a verdade só existe por meio de processos de criação, o que Nietzsche (2011, p. 357) designa como "[...] processus in infinitum, uma determinação ativa, e não manifestação da consciência de algo que seja em si fixo e determinado".

A verdade, para Nietzsche, não é algo a ser descoberto, mas a verdade "é uma coisa deste mundo" (SILVA, 2002, p. 39). Dito de outro modo, a ideia de verdade é uma criação do homem, que interpreta algo, por meio da linguagem. Assim, não se descobre algo, descreve-se algo, fruto de uma invenção (obra de um engendramento), por isso a interpretação é produtiva. Ao pensar a verdade como processo constante de criação, o autor problematiza o conhecimento, os processos de valoração, de universalizações, de naturalizações e de totalizações. Para Nietzsche, a verdade e o conhecimento são criados pelo homem e não estão desde sempre em algum lugar para serem descobertos e, por essa razão, deve-se inquirir de que modo determinadas verdades e conhecimentos foram criados, qual o processo de valoração pelo qual passaram. Contudo, essas criações não são atos isolados. "Elas passam a existir como atos de força, de imposição de sentido. [...] Sua dinâmica é movida pelo desejo - vital, impessoal anônimo - de dominar. [...] esse impulso, esse desejo, essa ânsia chama-se vontade de poder. É a vontade de poder que transforma o caos em ordem, a diferença em ser, a multiplicidade em unidade" (SILVA, 2002, p. 45).

Nietzsche, ao discutir os valores morais na própria teoria do conhecimento, alega que há um desprezo por tudo o que transmuta e a constante procura por estabelecer uma verdade, por "[...] um mundo que não se contradiga, que não engane nem transmute, um mundo-verdade - um mundo que não sofra: contradição, ilusão, mutação - causas do sofrimento" (NIETZSCHE, 2011, p. 362). Para o filósofo, esse mundo-verdade ou a vontade de saber busca fixar o conhecimento e evita o "sendo".

O saber paralisa aquilo que sem ele seria insuportável: movimento, fluxo, corrente. Pelo saber, a matéria em ebulição entra em estado de congelamento. O problema é que o saber tende a esquecer o estado de onde veio. O que era devir vira ser. O que era 'será?' vira 'é' [...] conhecer é reduzir o diferente ao igual (SILVA, 2002, p. 39-40).

$\mathrm{Na}$ visão de Nietzsche, o conhecimento só é possível num devir, como vontade de potência, no erro, na ilusão, na ficção e não pela crença de que o mundo é, de um mundo durável. É o jogo de forças que determinará o que chamamos de realidade e o que designamos como mentira, pois o mundo que chamamos de realidade é apenas aparência, no sentido de aparecer, e, em sua constante mudança, um conjunto de "apareceres". "Aí, então, reforçamos que Nietzsche não faz dualismos entre realidade e aparência, porque não temos outra coisa que somente aquilo que nos aparece efetivado pelas relações das forças" (SOUZA, 2009, p. 55).

O Mito da Caverna de Nietzsche, ou melhor, o Mito da Caverna de Platão, se lido com as lentes do pensamento nietzschiano, nos permite pensar que não só as sombras são aparências, mas que aquilo ou aqueles que produzem as sombras também são aparências. A questão do conhecimento deixa de ser a luta para descobrir e encontrar a verdade e passa a ser a indagação sobre o processo de valoração que elege como e quais aparências poderão ser reconhecidas como verdades. Desse modo, não há, como no mito da caverna de Platão, um mundo das aparências e o mundo da realidade, pois tanto as sombras quanto o processo de elaboração das sombras são aparências, são criações, portanto, são ficções. $O$ conhecimento deixa de ser compreendido como algo a ser descoberto e passa a ser tratado como algo a ser produzido, pois o ficcional "é uma potência que habita a produção, mesmo daquilo que é absolutamente palpável e material" (SILVA, 2014, p. 579). Ao conceber conhecimento e verdade como invenção, como criação, ou seja, como ficção, a performance joga com as fronteiras entre arte e vida, 
provocando pensar sobre os limites entre esses dois campos. Com efeito, a oposição entre ficção e real contradiz a própria noção contestadora de performance.

Os programas performativos seriam invenções, criações (ficções) que em geral buscam suspender as ficções entendidas como realidade e fixadas pelos regimes de verdade de um determinado tempo/espaço e/ou grupo social. Por consequência, ainda que um performer não busque representar um personagem, ficcionar um outro que não ele mesmo, ainda que elabore uma narrativa autobiográfica, apesar disso estará roteirizando, editando e compondo a si mesmo.

Ideia semelhante é defendida por Klinger (2008, p. 26), que compreende a escrita de si, os textos autoficcionais como performance, aduzindo que eles quebram o "[...] caráter naturalizado da autobiografia numa forma discursiva que ao mesmo tempo exibe o sujeito e o questiona, ou seja, que expõe a subjetividade e a escritura como processos de construção". De modo que a performance, conquanto invoque alguma teatralidade por vezes, em geral, posiciona-se como uma prática "antiteatral". A performance não busca que seu público compreenda uma história e dessa maneira se afete, como no teatro, ainda que muitas performances empreguem alguma teatralidade. Fabião apresenta a performance como uma pedra no sapato que altera nossas percepções, deriva nossas relações com nossos corpos, com objetos e com o meio. Porém, a intenção de alterar concepções não se restringe ao público, mas igualmente ao performer. Pois, [...] "um performer não apenas coloca propositalmente pedras no seu sapato, mas usa sapatos de pedra para que os fluxos ditos 'naturais' sejam interrompidos e outras maneiras de percepção e relação possam se desenvolver” (FABIÃO, 2009, p. 68).

Colocar uma pedra no sapato ou colocar sapatos de pedras para interromper (suspender) determinadas percepções, para que outros saberes possam emergir, é, em certa medida, abrir espaço para a invenção, para a criação, para novas e outras ficções. Assim, poder-se-ia compreender que a arte da performance nega a noção de ficção que antagoniza com um suposto real, justamente porque crê na vida como ficção, na vida como algo que se possa inventar.

A questão do conhecimento e da verdade, segundo Silva (2002, p. 37), é um dos pontos mais óbvios das teorizações tradicionais sobre currículo. Todavia, compreender o conhecimento e a verdade como construções, "[...] significa ver o conhecimento que está no seu centro não como representação de algo que está para além dele, mas como uma versão ou uma interpretação particular dentre as muitas que poderiam igualmente ser forjadas" (SILVA, 2002, p. 47). Sob esse prisma, poder-se-ia pensar que um currículo-performance, ainda que parta de um roteiro pré-estabelecido, de um programa elaborado intencionalmente, é composto por "[...] fendas, brechas interpretativas, formas de compreender o mundo, o outro, que não se esgotam pelo rigor do discurso lógico, racional, mas que antes convoca o corpo, as vísceras, a memória para uma real aproximação com esses" (PEREIRA, 2012, p. 307). Num currículo-performance, pode-se principiar de conhecimentos estabelecidos, mas eles não são o fim e sim disparadores para que coletiva e individualmente se produzam outros conhecimentos, atentando para o imprevisto, para as complexas relações que possam se estabelecer. Isso difere de um currículodocumento, no qual o conhecimento está pré-estabelecido e a expectativa é que a ele se chegue. A noção de ficção opera como um disparador para compreender os currículos não somente como os conteúdos elencados e dignos de fulgurar no espaço escolar, mas no conhecimento como um constante devir, sempre constituindo-se. Ou seja, o currículo não como o que está pré-escrito, mas como algo que está em constante escritura por meio das relações que se estabelecem entre os saberes e os corpos que habitam e atuam no espaço escolar. A noção de ficção em currículos-performance opera como um catalisador que nos suscita a "[...] viajar sem mapas prévios! Fazer outros traçados! [...] Fazer composições e conexões! Inventar [ficcionar] a cada vez suas orientações. Aprender! Gerar possibilidades de aprendizagem em contextos insuspeitos" (PARAÍSO, 2010, p. 602).

\section{CORPO E DOCUMENTO: PISTAS PARA CURRÍCULOS-PERFORMANCE}

O corpo tem centralidade nos Estudos da Performance, seja no que é designado como performance social, seja na arte da performance. Como já mencionado anteriormente, em ambas as acepções o corpo não se limita à constituição física, mas, igualmente, à construção das subjetividades, ou seja, os corpos também em certa medida se ficcionam. No campo dos Estudos da Performance, a 
principal produção intelectual de Victor Turner (1974) está ancorada na noção de teatralidade dos comportamentos sociais, que ele não encara como suposto fingimento, mas como um conjunto de comportamentos elaborados, repetidos e ritualizados, contrariando a ideia de comportamentos "naturais", "espontâneos", livres de artificialidade.

Um dos conceitos-chave para esses estudos foi o de conduta restaurada, de Schechner (2011). O autor explica a conduta restaurada por meio de uma analogia com o negativo de um filme e a ação do diretor, que pode alterar ou reconstruir a ordem dos acontecimentos sem manter a dependência com os "[...] sistemas causais (sociais, psicológicos, tecnológicos) que lhes deram origem" (SCHECHNER, 2011, p. 35) ${ }^{8}$. As condutas restauradas estão presentes em toda a representação, em toda sequência de acontecimentos elaborados, e estão distanciados do indivíduo. Seriam, portanto,

[...] ações programadas, textos conhecidos, movimentos pautados - existem independente dos atores que as realizam. Devido a isso, as sequências de conduta podem ser armazenadas, transmitidas, manipuladas e transformadas; os atores entram em contato com elas, as recuperam, recordam, ou inclusive, as inventam e logo voltam a comportar-se segundo os parâmetros, já sendo absorvidos [...] (SCHECHNER, 2011, p. 36) ${ }^{9}$.

No entanto, Schechner não compreende somente os comportamentos intencionais como condutas restauradas. Uma pessoa pode não estar consciente de estar realizando uma sequência de condutas restauradas, por exemplo, quando nos comportamos de acordo com o que aprendemos ser o correto em determinadas situações sociais. Dessa maneira, é possível compreender o conceito de conduta restaurada tanto como os comportamentos elaborados para rituais, manifestações artísticas, quanto como os comportamentos elaborados cotidianamente para as funções sociais que desempenhamos. A noção de condutas restauradas nos permite compreender que as performances tanto reforçam determinados saberes quanto abrem brechas para a produção de outras possibilidades. Por essa razão, ao elencar o corpo como um dos aspectos que compõem o que designamos de currículos-performance, não desejamos reforçar ou abordar a já tão enunciada inércia a que o corpo foi submetido desde a institucionalização da Escola, que, por sua vez, aprisionou o corpo na cadeira de forma a obrigá-lo a uma atenção necessária ao professor, que professa a palavra verdadeira. Tampouco não se deseja propor que os alunos exercitem os corpos entre um conteúdo e outro com o propósito de otimizar a aprendizagem. Defendemos, entrementes, que corpo e pensamento são inseparáveis na performance, o que parece que contradiz a disjunção tradicional da escola.

O corpo é o meio pelo qual, em geral, um performer realiza seu programa performativo. Desse modo, "[....] o performer é um criador de corpos individuais e coletivos, públicos e privados. Se o performer potencializa a relação com seu corpo é para disseminar uma reflexão e uma experimentação sobre a corporeidade do mundo, das relações, do pensamento" (FABIÃO, 2009, p. 63).

Os corpos na performance evidenciam a política, a ética, a moral, a história, reforçam ou suspendem determinados comportamentos. Da mesma forma que a Performance, o currículo, na concepção de Paraíso e Caldeira (2018, p. 13), pode ser concebido como "[...] um território político, ético e estético incontrolável que, se é usado para regular e ordenar, pode também ser território de escapes de todos os tipos, no qual se definem e constroem percursos inusitados, caminhos mais leves, trajetos grávidos de esperança a serem percorridos". Parece que a noção de corpo e currículo, nessas perspectivas, quase se tocam, se entrelaçam e, pelas lentes da ficção, nos permitem compreendê-los, tanto corpos quanto currículos, como processos construídos, nos distanciando dos processos de naturalizações e universalizações. Porém, pensar os corpos como constituintes de currículos, como produtores e transmissores de saberes e memórias, numa cultura como a nossa, centrada na escrita, no documento,

\footnotetext{
${ }^{8}$ No original em espanhol: “[...] sistemas causales (sociales, psicológicos, tecnológicos) que les dieron origen [...]" (SCHECHNER, 2011, p. 35).

9 No original em espanhol: “[...] acciones programadas, textos conocidos, movimientos pautados, - existen independientemente de los actores que las realizan. Debido a ello las secuencias de conducta pueden ser almacenadas, transmitidas, manipuladas y transformadas; los actores entran en contacto con ellas, las recobran, recuerdan o, incluso, las inventan y luego vuelven a comportarse según los parámetros ya siendo absorbidos [...]" (SCHECHNER, 2011, p. 36). 
no visível, enfim, numa cultura que Schneider (2011, p. 231) caracteriza como "ocularcêntrica", revelase um grande desafio.

A performance, contudo, para alguns autores, entre eles Phelan (2011), tem como uma de suas principais características o desvanecimento. Peggy Phelan (2011, p. 97), que parte de uma visão lacaniana, entende que:

A única vida da performance transcorre no presente da performance. A performance não se guarda, registra, documenta, nem participa de maneira alguma na circulação das representações: uma vez que se faça, se converte em outra coisa; já não é performance. Na medida em que a performance pretenda ingressar na economia da reprodução, trai e enfraquece a promessa de sua própria ontologia ${ }^{10}$.

Para a autora, o caráter ao vivo e irrepetivel é um ponto crucial em sua definição. Nessa perspectiva, um vídeo de uma performance não é uma performance, é um registro, mas não se trata do ato ao vivo (TAYLOR; FUENTES, 2011, p. 22). No entanto, essa visão é questionada tanto pelos performers que se valem do vídeo, da internet e da fotografia em suas criações quanto por teóricos, como Diana Taylor e Joseph Roach, que entendem a performance como "coparticipante da memória e da história". Para eles, "[...] a performance participa da transmissão que assegura a continuidade do saber" (TAYLOR; FUENTES 2011, p. 22) ${ }^{11}$. As abordagens metodológicas de Diana Taylor no que tange à performance, focam-se muitas vezes no caráter histórico das performances da América Latina e consideram tanto os arquivos (documentos, materialidades) quanto os repertórios (práticas de transmissão corpo a corpo) como materiais constituintes da performance. Para a autora, "[...] as performances funcionam como atos de transferência vitais, transmitindo o conhecimento, a memória e um sentido de identidade social, por meio do que Richard Schechner denomina 'condutas restauradas"” (TAYLOR, 2013, p. 27). De tal modo, como já referido no início deste texto, a autora considera performance como "[...] um sistema de aprendizagem, armazenamento e transmissão de conhecimento, os estudos da performance nos permitem ampliar o que entendemos por conhecimento" (TAYLOR, 2013, p. 45).

Entretanto, expandir nossa concepção de conhecimento nos exige abandonar a lógica do arquivo ou ao menos nos interrogar sobre ela. Para Schneider (2011, p. 226), é justamente porque pensamos sob a lógica do arquivo que conferimos à performance, aos saberes incorporados e aos corpos a desaparição como sua principal característica. Tal desaparição, no estatuto de valoração dos conhecimentos de nossa cultura, confere menor legitimidade às "[...] práticas de transmissão corpo a corpo. [...] Segundo essa lógica, ao permanecer sempre ao vivo, a transmissão corpo a corpo desaparece, se perde e, portanto, não há nenhuma transmissão" (SCHNEIDER, 2011, p. 227) ${ }^{12}$. Tal discussão remete à posição de valor que se confere ao currículo como documento, dá-se primazia ao visível. Difícil não evocar a história com a qual iniciamos este texto, na qual a discussão central era o modo pelo qual cada povo (romanos e gauleses) criava seus argumentos, que operavam como estatuto de verdade sobre os modos como preservavam suas memórias e transmitiam seus conhecimentos às novas gerações. Nós, assim como os romanos dos quadrinhos de René, operamos com a lógica do arquivo, do documento. Schneider (2011, p. 230) defende que, se entendemos a performance, as corporalidades como efêmeras, estamos reforçando a cultura que supõe que os documentos sofrem menos agenciamento que os corpos e, dessa forma, conservariam com maior eficiência memórias e conhecimentos. A transmissão oral e os saberes incorporados tendem a ser vistos como manifestações de povos primitivos ou sem escritas

\footnotetext{
10 Original em espanhol: "La única vida del performance transcurre en el presente. El performance no se guarda, registra, documenta ni participa de manera alguna en la circulación de las representaciones: una vez que lo hace, se convierte en otra cosa; ya no es performance. En la medida en que el performance pretenda ingresar en la economía de la reproducción, traiciona y debilita la promesa de su propia ontología" (PHELAN, 2011, p. 97).

${ }^{11}$ No original em espanhol: "[...] copartícipe de la memoria y la historia. [...] performance participa en la transmisión que asegura la continuidad del saber” (TAYLOR; FUENTES, 2011, p. 22).

${ }^{12}$ No original em espanhol: “[...] las prácticas de la transmisión cuerpo a cuerpo [...] Según esta lógica, al alojarse siempre en vivo, la transmisión cuerpo a cuerpo desaparece, se pierde, y por tanto no hay ninguna transmisión” (SCHNEIDER, 2011, p. 227).
} 
(SCHNEIDER, 2011, p. 230), e não como uma outra maneira de transmissão de memória e de produzir conhecimentos.

O que confere isenção ao documento seria o fato de se manterem íntegros ao longo de muitos anos. Não obstante, isso desconsidera que os documentos necessitam dos corpos para significar. Um documento escrito, por exemplo, ainda que permaneça o mesmo objeto ao longo dos anos, só cumpre sua função de transmissão ou produção de saberes por meio da leitura de alguém. Trata-se, então, do encontro de dois corpos e, assim, cada encontro produzirá uma narrativa, pois dependerá de quem o lê, no tempo em que foi escrito, no tempo/espaço no qual foi lido, do repertório linguístico do leitor, da alteração que decorre do tempo no sentido das palavras. Em suma, uma série de camadas no ato de leitura de um documento produz significações e dessa forma altera o documento. Destarte, o que confere o estatuto de confiabilidade ao documento é uma série de mitos, dos quais elencamos a seguir dois, apontados por Taylor (2013, p. 49). O primeiro deles corresponde ao exemplo anterior, a crença na isenção de um documento escrito, pois se desconsidera a mediação. Com efeito, no processo de significação de documentos arquivais há mediação, assim como há um processo de seleção, de escolha ou edição daquilo que será ou não considerado pertinente arquivar.

O segundo mito trata do suposto caráter indefectível, incorruptível e isento da manipulação. Esse segundo mito, para Taylor (2013, p. 49), é facilmente dissoluto, pois segundo ela os objetos podem aparecer e desaparecer como que por encanto dos arquivos. A autora afirma que ambos, documento e corpo, ou como ela designa, arquivo e repertório, sofrem agenciamentos, constituem partes das ficções que construímos em nossas culturas. A perspectiva da performance não vê como antagonistas documento e corpo, tampouco crê que há mais legitimidade em um do que no outro. Há em nossa sociedade fartos exemplos de práticas nas quais documentos e corporalidades atuam em conjunto - "[...] os casamentos precisam tanto da declaração performativa do 'sim' quanto do contrato assinado. A legalidade de uma decisão jurídica depende da combinação do julgamento ao vivo e do resultado registrado" (TAYLOR, 2013, p. 51).

Ao pensar performance sob essa perspectiva, abre-se uma multiplicidade de possibilidades que vão além da arte e que permitem pensar como os rituais institucionais, sua composição, os marcos históricos, os acontecimentos que não estão nos palcos, mas que potencializam a vida das pessoas, podem tanto manter determinados saberes quanto produzir outros. Em vista disso, o híbrido entre arte da performance e performance social nos currículos-performance seria compreendido tanto como um dispositivo de produção de protocolos normativos fixando saberes, quanto ações de resistência, ou reexistência a eles, ao suspender e mover os conhecimentos fixados.

$\mathrm{Na}$ história de Goscinny (2015), com a qual começamos este texto, romanos e gauleses defendem seus modos de transmissão e produção de conhecimento respectivamente pelo documento e pelo corpo. Parece-nos que o espaço entre os dois e as tensões que emergem nesse espaço seria bem mais produtivos para pensar os currículos escolares, ao entender que tanto documentos quanto corporalidades nos permitem ficcionar nossas histórias e nossos conhecimentos. De acordo com o que sugere Fabião, os diversos agenciamentos da performance instituem práticas "[...] voltadas para o exame e a vivência do 'entre'; são experimentos de formação, desformação, transformação do espaço, do tempo, dos corpos, do sentido, do mundo" (FABIÃO, 2013, p. XIII).

Ao compreender a ficção como invenção, criação, ainda que partamos de documentos em nossas práticas escolares, abrimos a possibilidade dos corpos coletiva e individualmente irem mais além do estabelecido, nos permitindo conceber que no espaço escolar não se aprende como o mundo é, mas como ele é criado. O mundo e a vida em constante movimento, distinto da percepção dual que fecha e fixa o conhecimento. Os currículos-performance movem-se, dançam entre e com documentos e práticas incorporadas. Há em um currículo

[...] vidas que se movem. Há todo um processo sendo vivenciado; que é o que realmente importa, porque no meio tudo se passa e porque o fim não existe! O que costumamos chamar de fim ou mesmo de resultado é sempre o fim de algo que continua de outra forma, portanto é a linha de mudança que habitualmente chamamos de fim (PARAÍSO, 2018, p. 28). 
O conhecimento então seria não para ensinar o que é o mundo, mas para perguntar como ele é constantemente constituído, a partir de quais perspectivas. Compreender o conhecimento como invenção, como constante devir, alude ao currículo não como algo que deve ser apreendido e fixado, mas como um fazer incessante, intrínseco ao vivido, aquilo que se torna corpo. De fato, o currículo seria, "[...] tal como a verdade, puro jogo de diferenças, infinito desdobrar-se de perspectivas e de interpretações, interminável baile de máscaras que nunca se detém para mostrar, finalmente, a 'verdadeira' face dos dançarinos e convidados" (SILVA, 2002, p. 48). As noções de ficção de Nietzsche, como invenção, e de corpo da performance, evidenciam o caráter efêmero do conhecimento, sem que isso seja tomado como o oposto da permanência. Acreditamos que a perspectiva da própria performance requisita uma relação com o conhecimento e a memória sem a pretensão ou intenção da permanência, mas compreendendo a efemeridade como parte constituinte da memória e do conhecimento. Os currículos-performance, sob esse ponto de vista, afastam-se da lógica do documento, que busca nos convencer de que apenas aquilo que permanece seria o próprio da escola.

A efemeridade evidenciada, por meio de currículos-performance, convoca o olhar para saberes invisibilizados pelos currículos-documentos. O processo de tornar visível o invisível confere valor não exclusivamente aos conhecimentos inventariados, mas ao processus in infinitum concernente à criação dos saberes. Tais processos reverberam nos corpos escolares, posto que professores e alunos, para além de reativar os conhecimentos já concebidos, agenciam-lhes e desse modo atuam como criadores.

\section{REFERÊNCIAS}

AGRA, Lúcio José de Sá Leitão. Performance e documento, ou o que chamamos por esses nomes?. Revista Brasileira de Estudos da Presença, Porto Alegre, v. 4, n. 1, p. 60-69, 2014. Disponível em: http://dx.doi.org/10.1590/2237-266041937. Acesso em: 02 jun. 2020.

ANDERSON, Gary L. A Reforma Escola como Espetáculo Político. Educação \& Realidade, Porto Alegre, v.35, n. 2, p.57-76, 2010.

ANDRÉ, Carminda Mendes. O Teatro Pós-dramático na Escola. 2007. Tese (Doutorado em Educação) - Programa de Pós-Graduação em Educação, Faculdade de Educação, Universidade de São Paulo, São Paulo, 2007.

ANDRÉ, Carminda Mendes. O que Pode a Performance na Escola. Cadernos Cedes, Campinas, v. 37, n. 101, p. 83-106, jan./abr. 2017.

ARAÚJO, Alan Livan. Práxis Intervencionista na Escola: experiências de ressignificação, deslocamento e insurgência. 2013. 140 f. Dissertação (Mestrado em Artes Cênicas) - Universidade Estadual Paulista Júlio de Mesquita Filho, Instituto de Artes, São Paulo, 2013.

AYERBE, Nerea. Documentando lo Efímero: reconsideración de la idea de presencia en los debates sobre la performance. Revista Brasileira de Estudos da Presença, Porto Alegre, v. 7, n. 3, p. 551572, 2017. Disponível em: http://dx.doi.org/10.1590/2237-266069648. Acesso em: 02 jun. 2020.

BALL, Stephen J. Performatividades e Fabricações na Economia Educacional: ruma a uma sociedade performativa. Educação \& Realidade, Porto Alegre, v35, n.2, p. 37-76, 2010.

BONATTO, Mônica Torres. Professor-performer, estudante-performer: notas para pensar a escola. 2015. Tese (Doutorado em Educação) - Faculdade de Educação, Programa de Pós-Graduação em Educação, Universidade Federal do Rio Grande do Sul, Porto Alegre, 2015. 
BONATTO, Mônica Torres; ICLE, Gilberto. Por uma pedagogia performativa: a escola como entrelugar para professores-performers e estudantes-performers. Cadernos Cedes, Campinas, v. 37, n. 101, p. 83106, jan./abr. 2017.

BONFITTO, Matteo. The Artist is Present: as artimanhas do visível. Revista Brasileira de Estudos da Presença, Porto Alegre, v. 4, n. 1, p. 83-96, 2014. Disponível em: http://dx.doi.org/10.1590/2237266042065. Acesso em: 03 jun. 2020.

CAON, Paulina Maria. Jogos, perfomances e performatividades na escola: das experiências corporais à problematização de discursos. Cadernos Cedes, Campinas, v. 37, n. 101, p. 107-130, jan./abr. 2017.

CIOTTI, Naira. O Híbrido Professor-performer: uma prática. 1999. Dissertação (Mestrado em Comunicação) - Programa de Comunicação e Semiótica, Pontifícia Universidade Católica de São Paulo, São Paulo, 1999.

CIOTTI, Naira. O Híbrido Professor-Performer. Natal: EDUFRN, 2014.

CONTE, Elaine. Aporias da Performance na Educação. 2013. Tese (Doutorado em Educação) Programa de Pós-graduação em Educação, Faculdade de Educação, Universidade Federal do Rio Grande do Sul, Porto Alegre, 2013.

COSTA, Hugo Heleno Camilo; LOPES, Alice Casemiro. A Contextualização do conhecimento no Ensino Médio: tentativas de controle do outro. Educação e Sociedade, Campinas, v. 39, n. 143, p. 301 320, abr./jun. 2018.

COSTA, Marisa Vorraber; WORTMANN, Maria Lúcia; BONIN, Iara Tatiana. Contribuições Dos Estudos Culturais Às Pesquisas Sobre Currículo - Uma Revisão. Currículo sem Fronteiras, Brasil; Portugal, v. 16, n. 3, p. 509-541, set./dez. 2016.

FABIÃO, Eleonora. Performance, Teatro e Ensino: poéticas e políticas da interculturalidade. In: FLORENTINO, Adilson; TELLES, Narciso (Org.). Cartografia do Ensino de Teatro. Uberlândia: EDUFU, 2009. p. 61-72.

FABIÃO, Eleonora. Entre. In: BONFITTO, Matteo. Entre o Ator e o Performer: alteridades, presenças, ambivalências. São Paulo: Perspectiva; Fapesp, p. XIII - XVIII, 2013.

FLUSSER, Vilém. Da Ficção. O diário de Ribeirão Preto, São Paulo, 26 ago. 1966. Disponível em: http://www.pgletras.uerj.br/matraga/matraga13/matraga13flusser.pdf. Acesso em: 14 set. 2019.

FRANGELLA, Rita de Cássia Prazeres. Um Pacto Curricular: O Pacto Nacional pela Alfabetização na Idade Certa e o Desenho de Uma Base Comum Nacional. Educação em Revista, Belo Horizonte, v. 32, n. 02, p. 69-89, abr./jun. 2016.

FREIRE, Paulo. Pedagogia do Oprimido. Rio de Janeiro: Paz e Terra, 1987.

GOSCINNY, René. O papiro de César. Texto de JeanYves Ferri; Ilustração de Didier Conrad. Tradução de Gilson Dimenstein Koatz. Rio de Janeiro: Record, 2015.

HARTMANN, Luciana. Pequenos Narradores e Suas Performances de Fascínio e Assombro. In: PEREIRA, Marcelo de Andrade (Org.). Performance e Educação: (des)territorializações pedagógicas. Santa Maria: Ed. da UFSM, 2013. p. 191-217. 
HARTMANN, Luciana. Desafios da diversidade em sala de aula: um estudo sobre performance narrativas de crianças imigrantes. Cadernos Cedes, Campinas, v. 37, n. 101, p. 83-106, jan./abr. 2017.

ICLE, Gilberto. Para Apresentar a Performance à Educação. Educação \& Realidade, Porto Alegre, v. 35, n. 2, p. 11-22, 2010.

ICLE, Gilberto. Estudos da Presença: prolegômenos para a pesquisa das práticas performativas. Revista Brasileira de Estudos da Presença, Porto Alegre, v. 1, n. 1, p. 9-27, 2011. Disponível em: http://dx.doi.org/10.1590/2237-266023682. Acesso em: 14 set. 2019.

ICLE, Gilberto. Da Performance na Educação: perspectivas para pesquisa e prática. In: PEREIRA, Marcelo de Andrade (Org.). Performance e Educação: (des)territorializações pedagógicas. Santa Maria: Ed. da UFSM, p. 09-22, 2013.

ICLE, Gilberto; BONATTO, Mônica; PEREIRA, Marcelo de Andrade. Performance e Escola. Cadernos Cedes, Campinas, v. 37, n. 101, p. 83-106, jan./abr. 2017.

KLINGER, Diana. Escrita de si como performance. Revista Brasileira de Literatura Comparada, Niterói, v. 10, n. 12, p. 11-30, 2008.

LOCKMANN, Kamila; TRAVERSINI, Clarice Salete. Alargamento das funções da escola e redefinição dos conhecimentos escolares: implicações da educacionalização do social. Revista Educação Pública Cuiabá, v. 26, n. 63, p. 817-835, set./dez. 2017.

MACEDO, Elizabeth. Currículo como Espaço-tempo de Fronteira Cultural. Revista Brasileira de Educação, Rio de Janeiro, v. 11, n. 32, maio/ago. 2006.

MACEDO, Elizabeth. Currículo e Conhecimento: aproximações entre educação e ensino. Cadernos de Pesquisa, São Paulo, v. 42, n. 147, p. 716-737, set./dez. 2012.

MACEDO, Elizabeth. Base Nacional Comum Curricular: a falsa oposição entre conhecimento para fazer algo e conhecimento em si. Educação em Revista, Belo Horizonte, v. 02, n. 32, p. 45-67, abr./jun. 2016.

MACHADO, Marina Marcondes. A criança é performer. Educação \& Realidade, Porto Alegre, v. 35, n. 2, p. 115-135, maio/ago. 2010.

MEDEIROS, Maria Beatriz. Performance, Charivari e Política. Revista Brasileira de Estudos da Presença, Porto Alegre, v. 4, n. 1, p. 47-59, 2014. Disponível em: http://dx.doi.org/10.1590/2237266041695. Acesso em: 14 set. 2019.

MOREIRA, Antonio Flávio Barbosa. Por entre ficções e descentramentos: discussões atuais de currículo e a psicologia da educação. Psicologia e Educação, São Paulo, v. 17, p. 11-36, 2003.

NIETZSCHE, Friedrich Wihelm. Vontade de Potência. Tradução de Mário Ferreira dos Santos. Petrópolis: Vozes, 2011.

OLIVEIRA, Thiago Ranniery Moreira; PARAÍSO, Marlucy Alves. Currículo, cultura e crueldade: para compor uma ética com Antonin Artaud e o teatro. Perspectiva, Florianópolis, v. 31, n. 2, p. 615-644, maio/ago. 2013.

PARAÍSO, Marlucy Alves. Diferença no currículo. Cadernos de Pesquisa, São Paulo, v. 40, n. 140, p. 587-604, maio/ago. 2010. 
PARAÍSO, Marlucy Alves. Metodologias de pesquisas pós-críticas em educação e currículo: trajetórias, pressupostos, procedimentos e estratégias analíticas. In: PARAISO, Marlucy Alves; MEYER, Dagmar (Org.). Metodologias de Pesquisas Pós-críticas em Educação. Belo Horizonte: Mazza, 2014.

PARAÍSO, Marlucy Alves. Relações de gênero no currículo da formação de professoras para a alfabetização: uma análise do Pacto Nacional pela Alfabetização na Idade Certa (PNAIC). In: PARAÍSO, Marlucy Alves; CALDEIRA, Maria Carolina da Silva (Org.). Pesquisas Sobre Currículos, gêneros e sexualidades. Belo Horizonte: Mazza, 2018.

PARAÍSO, Marlucy Alves; CALDEIRA, Maria Carolina da Silva (Org.). Pesquisas Sobre Currículos, gêneros e sexualidades. Belo Horizonte: Mazza, 2018.

PEREIRA, Marcelo de Andrade. Pedagogia da Performance: do uso poético da palavra prática educativa. Educação \& Realidade, Porto Alegre, v. 35, n. 2 p. 139-158, 2010.

PEREIRA, Marcelo de Andrade. Performance e Educação: relações, significados e contextos de investigação. Educação em Revista, Belo Horizonte, v. 28, n. 1, p. 289-312, mar. 2012.

PEREIRA, Marcelo de Andrade. Performance Docente: sentidos e implicações pedagógicas. In: PEREIRA, Marcelo de Andrade (Org.). Performance e Educação: (des)territorializações pedagógicas. Santa Maria: Ed. da UFSM, p. 23-36, 2013.

PEREIRA, Marcelo de Andrade. Pedagogia Crítico-performativa entre o próprio e o comum no espaçotempo-escolar. Cadernos Cedes, Campinas, v. 37, n. 101, p. 29-44, jan./abr. 2017.

PEREIRA, Marcelo de Andrade; CONTE, Eliane. Pedagogia da Performance: da arte da linguagem a linguagem da arte. In: PEREIRA, Marcelo de Andrade (Org.). Performance e Educação: (des)territorializações pedagógicas. Santa Maria: Ed. da UFSM, p. 95-114, 2013.

PEREIRA, Marcelo de Andrade; ICLE, Gilberto. Pedagogia performativa e seus não-lugares: reverberações da khôra a partir de Platão, Derrida e Agamben. Educar em Revista, Belo Horizonte, v. 34, p. 121-137, 2018.

PHELAN, Peggy. Ontologia del performance: representación sin reproducción. In: TAYLOR, Diana; FUENTES, Marcela. Estudios Avanzados de la Performance. México: FCE, Instituto Hemisférico de Performance y Política, Tisch School of the Arts, New York University, p. 93-121, 2011.

PINEAU, Elyse Lamm. Nos Cruzamentos Entre a Performance e a Pedagogia: uma revisão prospectiva. Educação \& Realidade, Porto Alegre, v. 35, n. 2, p. 89-114, 2010.

PINEAU, Elyse Lamm. Pedagogia Crítico-Performativa: encarnando a política da educação libertadora. In: PEREIRA, Marcelo de Andrade (Org.). Performance e Educação: (des)territorializações pedagógicas. Santa Maria: Ed. da UFSM, 2013. p. 37-58.

PINTO, Isabel. História do Teatro e Performance: a insurreição do arquivo como método. Revista Brasileira de Estudos da Presença, Porto Alegre, v. 5, n. 3, p. 507-532, 2015. Disponível em: http://dx.doi.org/10.1590/2237-266052244. Acesso em: 18 set. 2019.

RACHEL, Denise Pereira. Adote o artista não deixe ele virar professor: reflexões em torno do híbrido professor performer. 2013. 166 f. Dissertação (Mestrado em Artes) - Universidade Estadual Paulista Júlio de Mesquita Filho, Instituto de Artes, São Paulo, 2013. 
RACHEL, Denise Pereira. Cartografando as Performances do Professor. Cuerpo, Cultura y Movimento, Bogotá, v. 5, n. 2, p. 173-185, jul./dic. 2015.

ROQUES, Sylvie. O Corpo Performativo: questões da cena contemporânea. Revista Brasileira de Estudos da Presença, Porto Alegre, v. 7, n. 1, p. 4-18, 2017. Disponível em: http://dx.doi.org/10.1590/2237-266063634. Acesso em: 18 set. 2019.

SANTOS, Lucíola Licínio. Administrando o currículo ou os efeitos da gestão no desenvolvimento curricular. Educação em Revista, Belo Horizonte, n. 33, e166063, 2017. Disponível em: http://dx.doi.org/10.1590/0102-4698166. Acesso em: 18 set. 2019.

SCHECHNER, Richard. Performance: teoría y prácticas interculturales. Traducción: M Ana Diz. Buenos Aires: Libros del Rojas, 2000.

SCHECHNER, Richard. Restauración de la conducta. In: TAYLOR, Diana; FUENTES, Marcela. Estudios Avanzados de la Performance. México: FCE, Instituto Hemisférico de Performance y Política, Tisch School of the Arts, New York University, p. 31-50, 2011.

SCHECHNER, Richard; ICLE, Gilberto; PEREIRA, Marcelo de Andrade. O Que Pode a Performance na Educação. Educação \& Realidade, Porto Alegre, v. 35, n. 2, p. 23-36, 2010.

SCHNEIDER, Rebecca. El performance permanece. In: TAYLOR, Diana; FUENTES, Marcela. Estudios avanzados de la performance. México: FCE, Instituto Hemisférico de Performance y Política, Tisch School of the Arts, New York University, p. 217-239, 2011.

SILVA, Marose Leila e. Intervenção Artística na Escola Pública: reflexões de uma experiência na EMEF Des. Amorim Lima. 2012. 145 f. Dissertação (Mestrado em Artes) - Instituto de Artes, Universidade Estadual Paulista, São Paulo, 2012. Disponível em: http://hdl.handle.net/11449/86886. Acesso em: 2 abr. 2018.

SILVA, Rodrigo Lages. A ficção: uma aposta ético-política para as ciências. Fractal Revista de Psicologia, Niterói, v. 26, n. especial, p. 577-592, 2014.

SILVA, Tomaz Tadeu. Dr. Nietzsche Curriculista - com uma pequena ajuda do professor Deleuze. In: MOREIRA, Antonio Flávio; MACEDO, Elizabeth Fernandes de (Org.). Currículo, Práticas Pedagógicas e Identidades. Porto: Porto Editora, p. 35-51, 2002.

SILVA, Tomaz Tadeu. Documentos de Identidade: uma introdução às teorias do currículo. Belo Horizonte: Autêntica, 2010. (primeira edição 1999).

SOUZA, Mauro Araújo de. Nietzsche: viver intensamente, tornar-se o que se é. São Paulo: Paulus, 2009.

TAYLOR, Diana. O Arquivo e o Repertório: performance e memória nas Américas. Tradução de Eliane Lourenço de Lima Reis. Belo Horizonte: Editora UFMG, 2013.

TAYLOR, Diana; FUENTES, Marcela. Estudios avanzados de la performance. México: FCE, Instituto Hemisférico de Performance y Política, Tisch School of the Arts, New York University, 2011.

TRAVERSINI, Clarice; REIS, Júlia Milani; STEFFEN, Konstans. Potências e desafios da relação entre cegueira epistemológica e problematização para a pesquisa com a escola. Revista Educação e Cultura Contemporânea, Rio de Janeiro, v. 15, n. 39, p. 196-214, 2018. 
TRAVERSINI, Clarice Salete. O Desencaixe como Forma de Existência da Escola Contemporânea. In: SARAIVA, Karla; MARCELLO, Fabiana de Amorin (Org.). Estudos Culturais e Educação: desafios atuais. Canoas: Ulbra, p. 173-186, 2012.

TURNER, Victor W. O Processo Ritual: estrutura e anti-estrutura. Tradução de Nancy Campi de Castro. Petrópolis: Vozes, 1974.

VEIGA-NETO, Alfredo. Currículo e Cultura. Contrapontos, Itajaí, ano 2, n. 4, p. 43-51, jan./abr. 2002.

VEIGA-NETO, Alfredo. Currículo, Cultura e Sociedade. Educação Unisinos, São Leopoldo, v. 5, n. 9, p. 157-171, jul./dez. 2014.

Submetido: $15 / 04 / 2019$

Aprovado: 19/10/2019 